\title{
Gender inclusive sporting environments: the proportion of women in non-player roles over recent years
}

\author{
R Eime ${ }^{1,2^{*}}$, M Charity $^{1}$, B. C Foley ${ }^{3}$, J Fowlie ${ }^{1}$ and L. J Reece ${ }^{3}$
}

\begin{abstract}
Background: Throughout the ecosystem of sport, women have been and continue to be underrepresented at all levels compared to men. The capacity of community-level sport is heavily reliant on the many non-player roles including governance, as well as administration, coaching and officiating. Recently there has been increased attention to improving the gender balance in sport. The aim of this study is to investigate the proportions of women engaged in non-playing roles in sport (2016-2018).

Methods: This study involved secondary analysis of the AusPlay survey, a national population survey, funded by Sport Australia. This study utilised data from people aged 15-years or older about their involvement in non-playing roles in sport, and their demographic data. Survey respondents were asked "During the last 12 months, have you been involved with any sports in a nonplaying role, such as official, coach, referee, administrator, etc?" Analysis of non-player role responses focussed specifically on the top four non-player role categories; coach, official, administrator and manager. Frequency analysis concentrated on the distribution of men and women involvement in a non-player capacity for the three years, with detailed analysis of the most recent year (2018).
\end{abstract}

Results: In this study of 61,578 Australians there was a higher proportion of men in non-player roles in sport compared to women, across each of the three years (2018: men $55 \%$, women $46 \%$ ). Involvement of women in coaching increased significantly from $38 \%$ to 2016 to $44 \%$ in $2018(p<0.001)$. The proportion of women involved in administration roles significantly decreased from a peak of $51 \%$ in 2017 to $46 \%$ in $2018(p<0.001)$.

Conclusions: Aligned with strategic policy and investment strategies, there are gradual increased representation of women in non-playing sport, coaching roles. Women are still underrepresented in terms of coaches, officials and administrators, but are more likely to be managers. It is recommended that there is continued mentoring, identification and emphasising of female role models, and further strategies to increase female presence in nonplaying roles. We recommend that future research, in line with appropriate gender and cultural-change theories, investigates and discusses the progress of gender equality throughout playing and non-playing role in sport.

Keywords: Community sport, Volunteer, Gender, Coaches, Administrators

\footnotetext{
* Correspondence: r.eime@federation.edu.au

'School of Science, Psychology and Sport, Federation University, Ballarat,

Australia

Institute for Health and Sport, Victoria University, Footscray, Australia

Full list of author information is available at the end of the article
}

(c) The Author(s). 2021 Open Access This article is licensed under a Creative Commons Attribution 4.0 International License, which permits use, sharing, adaptation, distribution and reproduction in any medium or format, as long as you give appropriate credit to the original author(s) and the source, provide a link to the Creative Commons licence, and indicate if changes were made. The images or other third party material in this article are included in the article's Creative Commons licence, unless indicated otherwise in a credit line to the material. If material is not included in the article's Creative Commons licence and your intended use is not permitted by statutory regulation or exceeds the permitted use, you will need to obtain permission directly from the copyright holder. To view a copy of this licence, visit http://creativecommons.org/licenses/by/4.0/ The Creative Commons Public Domain Dedication waiver (http://creativecommons.org/publicdomain/zero/1.0/) applies to the data made available in this article, unless otherwise stated in a credit line to the data. 


\section{Background}

Inclusion throughout all layers of the sport ecosystem, where people have the opportunity to participate to their desired capacity without discrimination, is an important part of a fair society. Participation in sport in both playing (athlete/participant) and non-playing (coaches/officials/ administration/governance) roles are associated with positive individual, social, strategic and economic benefits $[1,2]$. However, women and girls have historically been, and continues to be, an underrepresented throughout sport, $[3,4]$ in both playing and non-playing roles such as coaches and board members [5].

In terms of participation in community sport, males participate at twice the rate of females [3]. In general, it is argued that gender is a highly visible position of inequality in sport [6], and historically this disparity in participation across gender reflects the societal perceptions that sport participation is part of a typical male domain [7]. Further the negative stereotypes about women playing sport affects the sports activities that women and girls participate in and specifically for those sports that at traditionally male dominated or considered suited to males [7]. These negative stereotypes are also amplified with a lack of female representation in sport media, and specifically in traditionally male dominated sports [8].

An international study of gender diversity in sport governance reports that across 45 countries women remain underrepresented as board directors (global average $20 \%$ ), board chairs (11\%) and chief executives $(16 \%)$. Few countries achieved a critical mass of women in leadership roles [9]. There is strong evidence that gender diversity on corporate boards has a positive impact through a range of processes and business outcomes as well as being important role models for other women [10].

In Australia, grass-roots sports are often community run, not for profit organisations. Across grass-roots sports there are over 2.3 million people [11] involved in non-playing roles, paid or unpaid roles, who collectively contribute to the capacity of the organisation and deliver their sport $[12,13]$. The majority of research to date which has focused on the sport workforce refers to them as 'volunteers', however, this insinuates that they are not paid for their time, when in fact roles such as coaches, officials and administrators may be paid. As such, in this study will use the collective term 'non-playing' roles for both paid and voluntary roles which enable players to participate throughout the sport ecosystem including sport governance, sport administration, coaching and officiating as well as playing.

Within community grass-roots sport, the motivations for involvement in non-playing roles include networking, having a child playing the sport, as well as other extrinsic benefits such as awards and recognition from others
[14-17]. Other key drivers to their involvement include a general interest in the sport, and a desire to help others or to give back to a club or community $[14,15]$. In addition to the benefits of people in non-playing roles to run sports clubs, their participation can positively impact individuals. For example their involvement can provide a sense of belonging, sense of satisfaction, workrelated experience, new relationships and an increased sense of self $[14,18,19]$.

Involvement in non-playing roles in sport has historically been dominated by men (aged 35-54 years) with few women involved [11]. The masculine hegemony in sport can influence how gender operates as an organising principle in leadership in sports organisations [5]. As a result women are often overlooked for sports coaching, officiating and governance roles [20-23]. This is sometimes due to a presumption that women sports coaches do not have the same skillset and attributes as male coaches such as toughness, strength, competitiveness, aggressiveness and loudness, and opinions that women are incapable of coaching sport [21, 24]. Even within women's sport, men are often the head coaches [20]. A lack of role models for women in non-playing sports roles can hinder their involvement [25].

Recently, the importance of gender diversity in nonplaying roles in sport from chief executive officers, board members through to coaches and officials has been highlighted by government and as such various policies and strategies have been developed and implemented [26-28]. For example, in Victoria, Australia there are numerous programs aimed at sports organisations tackling gender inequality on and off the playing field. This includes a Five Year Game Plan, which aims to encourage the sports sector to challenge gender stereotypes and encourage more women and girls to reach their full potential, and includes a range of initiatives including funding for female friendly sports infrastructure and quotas for women on boards [28]. Another example of commitment to gender equality in sport policy is in New Zealand, which focuses on.

increasing female participation at all levels, in sport and recreation in addition to recognising the power that gender balance has to positively change social, economic and culture future of countries [29].

Given these recent government initiatives which focus on gender inclusive sports environments, the aim of this study is to investigate the proportions of women engaged in non-playing roles in sport over recent years.

\section{Methods}

This study involved secondary analysis of the AusPlay survey, a national population survey, funded by Sport Australia [30]. It has been conducted annually from 2015 by computer assisted telephone interviewing to 
find out about participation in sport and other physical activities in Australia. The survey invites adults $(15+$ years old) to provide participation behaviours, motivations, barriers, use of technology, involvement in nonplaying roles and demographic data.

Randomly selected Australians aged 15 and over were interviewed, with additional questions for children being asked of the main respondent when they were parents or guardians of at least one child in their household. The adult (15 plus) with the most recent birthday was selected for interview when a landline telephone was called. For mobile phone contact, the owner of the mobile was selected. The Sample Pages database was used to produce sampling frames for the random generation of phone numbers to call. Weights for the adult (15 plus) data were determined by geographic strata, age, gender and corresponding Estimated Residential Population (ERP) [30].

Survey respondents were asked "During the last 12 months, have you been involved with any sports in a nonplaying role, such as official, coach, referee, administrator, etc?" Each they responded "Yes", subsequent questions asked them to describe up to three sports they were involved with, and the non-player role or capacity they fulfilled in each sport. Analysis of non-player role responses focussed specifically on popular non-player role categories; namely coach, official, administrator and manager. The definitions of each role are: 'coach' refers to coaches, instructors, trainers or teachers; 'official' includes roles such as referees, umpires, scorers, timekeeper and line judge; 'administrator' consists of committee members and sport administrators; 'manager' comprises of team managers and coordinators. If an individual performed in more than one role, these were counted separately.

Frequency analysis concentrated on the distribution of men and women involvement in a non-player capacity for the three years 2016, 2017 and 2018, with detailed analysis of the most recent year (2018). In line with international and national recommendations, $50 \%$ was considered acceptable representation of women and men in sport [27, 31]. Additional testing examined if having children under 15 years of age, being physically active yourself (at least once in past 12 months), or living in different States/Territories of Australia changed this distribution. Being physically active was defined from the question: In the last 12 months did you participate in any physical activities for sport, for exercise, or for recreation.

All analyses were weighted as per AusPlay method instructions and run in STATA 13.

\section{Results}

Table 1 summarises the demographics of the survey participants who indicated that they participated in a nonplayer role within sport (Table 1). The numbers
Table 1 Demographics for those undertaking any non-player role

\begin{tabular}{|c|c|c|c|c|c|c|}
\hline & \multicolumn{2}{|l|}{2016} & \multicolumn{2}{|l|}{2017} & \multicolumn{2}{|l|}{2018} \\
\hline & $\mathrm{n}$ & $\%$ & $\mathrm{n}$ & $\%$ & $\mathbf{n}$ & $\%$ \\
\hline & $2,849,402$ & 100.0 & $2,898,326$ & 100.0 & $3,109,126$ & 100.0 \\
\hline \multicolumn{7}{|c|}{ Participate in physical activity } \\
\hline Yes & $2,730,672$ & 95.8 & $2,780,003$ & 95.9 & $3,019,215$ & 97.1 \\
\hline No & 118,730 & 4.2 & 118,323 & 4.1 & 89,911 & 2.9 \\
\hline \multicolumn{7}{|l|}{ Gender } \\
\hline Male & $1,639,394$ & 57.5 & $1,631,732$ & 56.3 & $1,693,922$ & 54.5 \\
\hline Female & $1,210,008$ & 42.5 & $1,266,594$ & 43.7 & $1,415,204$ & 45.5 \\
\hline \multicolumn{7}{|c|}{ Child(ren) under 15} \\
\hline yes & $1,172,783$ & 41.2 & $1,123,172$ & 38.8 & $1,249,709$ & 40.2 \\
\hline
\end{tabular}

presented are weighted numbers. There was a total of 61,578 study participants and 8,016 who reported that they were involved in at least one non-player sport roles. Nearly all the non-player role people also had participated in physical activity at least once in the previous year, and this increased from 95.8 to 2016 to 97.1 in 2018. There were more males than females across each of the three years, however the proportion of females increased, whilst the proportion of males decreased from 2016 to 2018. Under half of those in non-player roles had children aged under 15 years. Due to the large, weighted numbers, most significance testing has resulted in significant differences.

Figure 1 shows the proportion of women involved in sport in non-playing roles across 2016, 2017 and 2018. Involvement of women in coaching increased significantly from $38 \%$ to 2016 to $39 \%$ in 2017 and $44 \%$ in $2018(p<0.001)$. Additionally, proportion of women involved in administration roles significantly decreased from $51 \%$ to 2017 to $46 \%$ in $2018(p<0.001)$.

Further analysis of non-playing roles by gender in 2018 found that managers are most likely to be female (64\%), whereas coaches, officials and administrators are most likely males (56\%, 61 and $54 \%$ respectively) $(p<0.001)$ (Fig. 2$)$.

Table 2 shows the percentage breakdown of men and women in the roles of administrator, coach, official and manager by Australian States/Territories. Most States and Territories in Australia display gender equitable representation in Administration, coaching and officials' roles in sport. Women were underrepresented as Administrators in Western Australia (38.5\%), Coaches in Victoria (37.9\%), Official's in Queensland (30.8\%) and Managers in the Northern Territory (27.7\%). Managers were predominantly women in six jurisdictions, with less than one in five managers in Western Australia and Tasmania being men.

There are different patterns of gender diversity in nonplayer roles according to having children aged under 15 


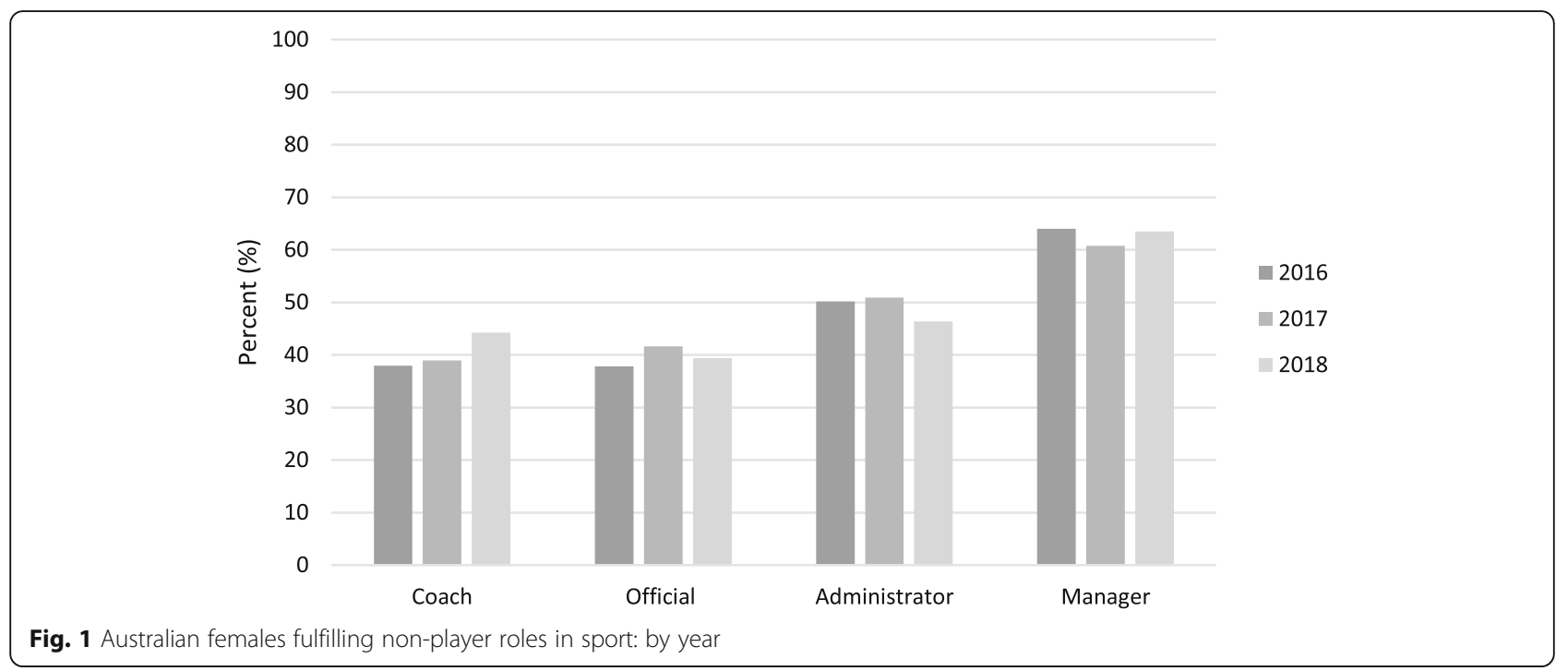

years. Among people who had children aged 15 years or younger, $72 \%$ of team manager or coordinator roles were fulfilled by women. Whereas $40 \%$ of coaching or officiating roles were fulfilled by women with children, compared to $60 \%$ of men with children. Administrative or committee member roles, were fulfilled by $59 \%$ women and $41 \%$ men, with children.

In all non-playing roles, women had higher participation when they were also a player in the sport. Whereas for men, their participation in non-player roles was higher when they were not a player in the sport.

\section{Discussion}

Historically, men have dominated sport at all levels including as board directors, chief executive officers, officials, coaches as well as players. The aim of this study was to investigate the proportions of women engaged in non-playing roles in sport over recent years. Given the recent policy and strategic developments aimed at achieving gender equity in sport $[27,28]$, this study provides further insights into the roles available in sport beyond playing, with a focus on gender. Individuals in non-playing roles are critical in building sustainable sporting communities [32]. Additionally, having diversity among roles can improve sport through acceptance and changing traditional values and practises [9].

This current study demonstrates that there has been an increase in involvement of women in coaching over a short period from 2016 to 2018 with $38 \%$ of coaches being women in 2016 compared to $44 \%$ in 2018 . The earlier, 2016 figure is similar to that reported in an American study of intercollegiate sports teams, with

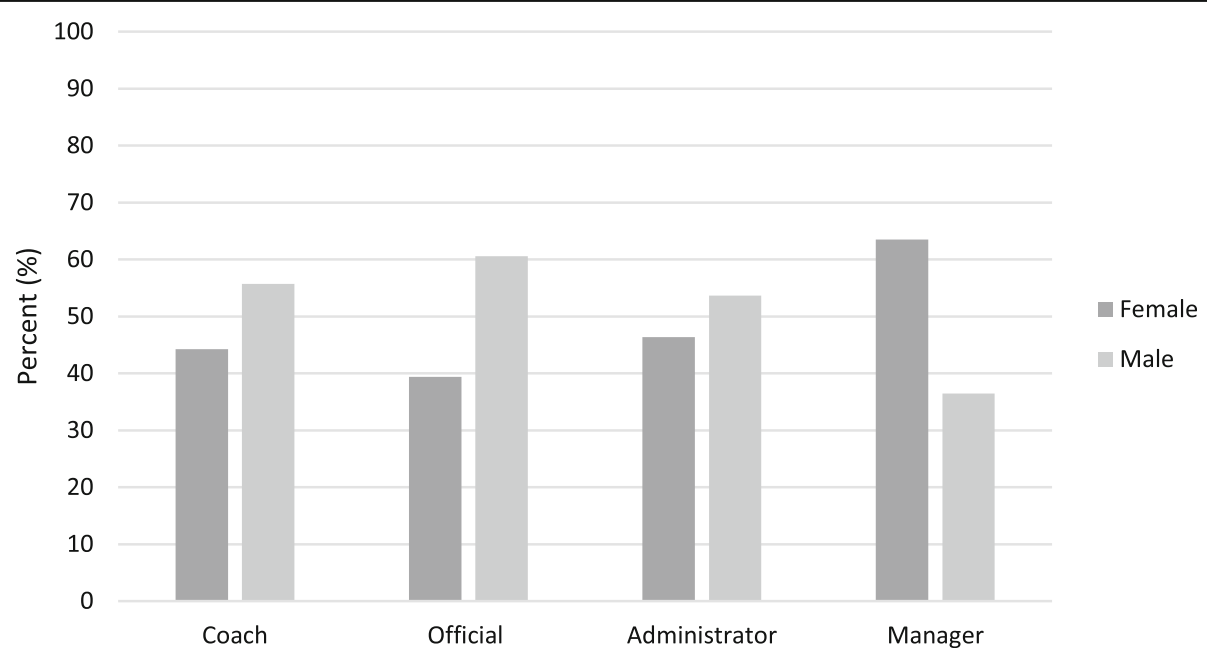

Fig. 2 Non-playing roles, 2018: by gender 
Table 2 Non-playing roles, 2018: by state and gender

\begin{tabular}{|c|c|c|c|c|c|c|c|}
\hline \multirow[b]{2}{*}{ Role } & \multirow[b]{2}{*}{ State } & \multicolumn{2}{|l|}{ female } & \multicolumn{2}{|l|}{ male } & \multicolumn{2}{|l|}{ person } \\
\hline & & $n$ & $\%$ & $n$ & $\%$ & $n$ & $\%$ \\
\hline \multirow[t]{8}{*}{ Administrator } & Australian Capital Territory & 4,774 & 41.7 & 6,681 & 58.3 & 11,455 & 100.0 \\
\hline & New South Wales & 78,674 & 47.3 & 87,598 & 52.7 & 166,272 & 100.0 \\
\hline & Northern Territory & 2,267 & 70.4 & 954 & 29.6 & 3,221 & 100.0 \\
\hline & Queensland & 73,713 & 54.9 & 60,671 & 45.1 & 134,384 & 100.0 \\
\hline & South Australia & 29,993 & 49.9 & 30,108 & 50.1 & 60,101 & 100.0 \\
\hline & Tasmania & 5,026 & 43.2 & 6,618 & 56.8 & 11,644 & 100.0 \\
\hline & Victoria & 78,248 & 41.5 & 110,413 & 58.5 & 188,660 & 100.0 \\
\hline & Western Australia & 29,063 & 38.5 & 46,345 & 61.5 & 75,407 & 100.0 \\
\hline \multirow[t]{8}{*}{ Coach } & Australian Capital Territory & 13,738 & 52.5 & 12,424 & 47.5 & 26,162 & 100.0 \\
\hline & New South Wales & 227,406 & 41.8 & 317,064 & 58.2 & 544,470 & 100.0 \\
\hline & Northern Territory & 20,034 & 85.7 & 3,349 & 14.3 & 23,383 & 100.0 \\
\hline & Queensland & 145,183 & 46.8 & 164,978 & 53.2 & 310,160 & 100.0 \\
\hline & South Australia & 49,665 & 46.5 & 57,185 & 53.5 & 106,851 & 100.0 \\
\hline & Tasmania & 21,382 & 58.1 & 15,399 & 41.9 & 36,781 & 100.0 \\
\hline & Victoria & 147,070 & 37.9 & 241,015 & 62.1 & 388,085 & 100.0 \\
\hline & Western Australia & 100,970 & 49.9 & 101,467 & 50.1 & 202,437 & 100.0 \\
\hline \multirow[t]{8}{*}{ Official } & Australian Capital Territory & 8,100 & 40.0 & 12,169 & 60.0 & 20,270 & 100.0 \\
\hline & New South Wales & 140,531 & 41.1 & 201,360 & 58.9 & 341,891 & 100.0 \\
\hline & Northern Territory & 1,971 & 63.0 & 1,158 & 37.0 & 3,129 & 100.0 \\
\hline & Queensland & 65,307 & 30.8 & 146,394 & 69.2 & 211,701 & 100.0 \\
\hline & South Australia & 39,992 & 48.5 & 42,524 & 51.5 & 82,516 & 100.0 \\
\hline & Tasmania & 9,709 & 35.9 & 17,355 & 64.1 & 27,064 & 100.0 \\
\hline & Victoria & 118,142 & 40.6 & 173,169 & 59.4 & 291,312 & 100.0 \\
\hline & Western Australia & 51,629 & 40.7 & 75,210 & 59.3 & 126,839 & 100.0 \\
\hline \multirow[t]{8}{*}{ Manager } & Australian Capital Territory & 8,977 & 69.9 & 3,861 & 30.1 & 12,838 & 100.0 \\
\hline & New South Wales & 85,881 & 66.1 & 43,969 & 33.9 & 129,851 & 100.0 \\
\hline & Northern Territory & 867 & 27.7 & 2,258 & 72.3 & 3,125 & 100.0 \\
\hline & Queensland & 47,053 & 56.8 & 35,723 & 43.2 & 82,775 & 100.0 \\
\hline & South Australia & 27,226 & 63.9 & 15,403 & 36.1 & 42,629 & 100.0 \\
\hline & Tasmania & 2,552 & 84.1 & 483 & 15.9 & 3,035 & 100.0 \\
\hline & Victoria & 79,823 & 58.5 & 56,563 & 41.5 & 136,386 & 100.0 \\
\hline & Western Australia & 40,113 & 80.7 & 9,595 & 19.3 & 49,708 & 100.0 \\
\hline
\end{tabular}

$35 \%$ of coaches being women [33]. Whilst the proportion of women coaches increasing in Australia is a positive, it is also positive that other cultural and societal acceptance of female coaches seems to be improving. A recent study of male college athletes reported that the gender of their coach was not important, as long as they were a competent coach [22]. However, there are a range of barriers for women in coaching roles including a lack of support, inadequate salary, job insecurity, as well as difficulties in working with parents/spectators and coaching at weekends and evenings [34]. There is growing body of evidence that females in sport benefit from other female role models, both in participation and in coaching or non-player roles, and that female players often prefer female coaches $[8,35]$.

This current study shows that women's involvement in administrative roles has decreased from $50 \%$ to 2016 compared to $46 \%$ in 2018, although this shift may not be cause for concern. These roles include committee members as well as sports administrators. The increased proportion of men in administrative roles may suggest a change in historical societal norms. It is not clear why there would be a change in the proportion of women in administrative roles in sport, however it may be that 
there has been a redistribution of women across the sports, moving from administration to other non-player roles. A study of sport administrators at a higher level national governing bodies, investigated female development in sport administration, and found that interpersonal relationships with supervisors, mentors and access to professional development helped them to progress [36]. Similar strategies which foster female development in administrative and other non-players roles should be implemented to enhance gender equity throughout the sport sector.

Many people involved in non-playing roles, particularly in youth sport, are parents [18]. This study demonstrated that males and females with children (aged under 15) take on different roles. For those with children, females were much more likely to be team managers or coordinates and administrators or committee members and much less likely to be coaches or officials, compared to males. This may be reflected by the societal gender expectations and norms where females are generally the primary care-giver [37]. It may be that coaching roles are more time pertinent especially with structured times for training and competition, whereas other non-playing roles are less structured time dependent, and more flexible and preferred by females.

The results of this study also highlight that the proportion of women in non-player roles in sport do differ across the States and Territories of Australia. This could be related to different policies and strategic priorities across the different jurisdictions. Future research should investigate specific reasons for these state-based differences and what facilitates gender equity in the national sport sector.

Participation in sport in the capacity as a player can also have an indirect influence on the transition of players to coaches and officials for females. We found that for females, their participation in non-playing roles was higher when they were active themselves. It may be that females are more confident to be involved in nonplaying roles if they themselves are active too.

Culture in sport has traditionally been masculine and this does influence the number of women in both playing and non-playing roles in sport [5]. The results of this study demonstrate that with an international and Australian specific strategic focus on more women in leadership or non-playing roles in sport, we can see gradual changes, but cultural change does take time. Having said that, because men still hold most of the senior management positions in sport, they therefore still possess most of the power [38]. Recent research suggests that a culture that promotes inclusion of women in sport at all levels can enhance visibility and encourage role models in non-player roles to support female participation [8]. This is supported by other international sport management research which discusses the role of sport in shaping cultural discourse and processes that drive and facilitate change [39]. However, the culture of sport still perpetuates sexism including diminishing and objectifying women's capabilities [40]. Another example is sexist language towards women and girls which often reinforces the position of men dominating the sporting landscape [41]. We need continued sport policy and strategies utilising a top-down and bottom-up approach that supports women and girls in non-playing roles within sport for increased diversity in decision making.

There are some limitation in this study to be acknowledged. Firstly, the survey was limited to persons aged 15 years or more. However, non-playing roles as presented in this study are most likely adults. Further, the survey like all survey-based research is likely to include a response bias. Those people engaged in sport are probably more likely to agree to participate in a survey related to participation in sport [42].

\section{Conclusions}

In conclusion, aligned with strategic policy and investment strategies, representation of women in non-playing sport roles have gradual increased. However, women are still underrepresented in terms of coaches, officials and administrators compared to males, but are more likely to be managers. This study highlights that women are more likely to be involved in non-playing roles if they themselves are active or have young children who participate in sport. It is recommended that there is continued mentoring, identification and emphasising of female role models, and other strategies to increase female presence in non-playing roles. This is important for not only the non-playing roles, but also for women and girls to participate throughout the sport ecosystem. Change can occur, but it takes time. Further, we recommend that future research, in line with appropriate gender and cultural-change theories, investigates and discusses the progress of gender equality throughout playing and nonplaying role in sport.

\section{Acknowledgements \\ The authors thank Sport Australia for providing access to AusPlay data.}

\section{Authors' contributions}

In collaboration, all authors conceptualised the study and developed the initial research plan. MJC, contributed to the study design, conducted the data analysis and results and critically reviewed the manuscript. RE, BCF, JF and $\operatorname{LR}$ contributed to the study design, interpretation of the results and drafted of the manuscript. All authors read and approved the final version of the manuscript for publication.

\section{Funding}

No external funding was received for this study. The SPRINTER research group receive funding from Sport Australia for research and evaluation of their Move it AUS grant program. 


\section{Availability of data and materials}

The data were provided by Sport Australia and access to the data would need to be sought from Sport Australia. The research team have a data agreement with Sport Australia to conduct analysis and reporting of AusPlay data.

\section{Declarations}

\section{Ethics approval and consent to participate}

Ethics approval was granted by the Human Research Ethics Committee of the Federation University, Australia [C13-007], for secondary data analysis of de-identified data which had been collected by the primary data custodians. Verbal informed consent to the questionnaire was indicated by respondents' agreement to participate in the telephone survey. In this government conducted national survey children were defined as aged less than 15 years, and the child questionnaire was completed by an adult parent or guardian.

\section{Consent for publication}

Not applicable.

\section{Competing interests}

The authors declare that they have no competing interests.

\section{Author details}

'School of Science, Psychology and Sport, Federation University, Ballarat, Australia. ${ }^{2}$ Institute for Health and Sport, Victoria University, Footscray, Australia. ${ }^{3}$ Charles Perkins Centre, School of Public Health, Faculty of Medicine and Health, SPRINTER, Prevention Research Collaboration, The University of Sydney, Sydney, Australia.

\section{Received: 10 September 2020 Accepted: 23 May 2021}

\section{Published online: 28 May 2021}

\section{References}

1. Davies L, Taylor P, Ramchandani G, Christy E, Social Return on Investment in Sport: A participation wide model for England. 2016, Sport Industry Research Centre- Sheffield Hallam University. p. 15.

2. Robertson J, Eime R, Westerbeek H. Community sports clubs: are they only about playing sport, or do they have broader health promotion and social responsibilities? Annals of Leisure Research; 2018.

3. Eime R, Harvey J, Charity M, Payne W. Population levels of sport participation: implications for sport policy. BMC Public Health. 2016;16(1):18.

4. Borgers J, Vanreusel B, Lefevre J, Scheerder J. Involvement in non-club organized sport: organizational patterns of sport participation from a longitudinal life course perspective. European Journal for Sport Society. 2018;15(1):58-77.

5. Burton LJ. Underrepresentation of women in sport leadership: A review of research. Sport Management Review. 2015;18(2):155-65.

6. Spaaij R, Farquharson K, Marjoribanks T. Sport and social inequalities. Sociology Compass. 2015;9(5):400-11.

7. Gentile A, Boca S, Giammusso I. 'You play like a Woman!' Effects of gender stereotype threat on Women's performance in physical and sport activities: A meta-analysis. Psychol Sport Exerc. 2018;39:95-103.

8. Fowlie J, Eime RM, Griffiths K. Barriers to adolescent female participation in cricket. Annals of Leisure Research, 2020: p. 1-19.

9. Adriaanse J. Gender Diversity in the Governance of Sport Associations: The Sydney Scoreboard Global Index of Participation. J Bus Ethics. 2016;137(1): 149-60.

10. Terjesen S, Sealy R, Singh V. Women Directors on Corporate Boards: A Review and Research Agenda. Corporate Governance: An International Review. 2009;17(3):320-37.

11. Australian Bureau of Statistics. Volunteers in sport. Australian Bureau of Statistics; 2012.

12. Casey M, Fowlie J, Charity M, Harvey J, Eime R. The implications of female sport policy developments for the community-level sport sector: a perspective from Victoria, Australia. International Journal of Sport Policy and Politics, 2019: p. 1-22.

13. Jenkin C, Eime R, Westerbeek H, O'Sullivan G, van Uffelen J. Are they 'worth their weight in gold'? Sport for older adults: benefits and barriers to their participation for sporting organisations. International journal of sport policy politics. 2016;8:663-80.

14. Bradford S, Hills L, Johnston C. Unintended volunteers: the volunteering pathways of working class young people in community sport. International Journal of Sport Policy Politics. 2016;8(2):231-44.

15. Cuskelly G, Hoye R. Sports officials' intention to continue. Sport Management Review. 2013;16(4):451-64.

16. Engelberg T, Skinner J, Zakus D. What does commitment mean to volunteers in youth sport organizations? Sport in Society. 2014;17(1):52-67.

17. Kim E, Fredline L, Cuskelly G. Heterogeneity of sport event volunteer motivations: A segmentation approach. Tour Manag. 2018;68:375-86.

18. Cuskelly G, O'Brien W. Changing roles: applying continuity theory to understanding the transition from playing to volunteering in community sport. European Sport Management Quarterly. 2013;13(1):54-75.

19. Volunteering, Australia, Response on a National Sports Plan. 2017.

20. Schlesinger T, Weigelt-Schlesinger Y. Coaching soccer is a man's job!"-The influence of gender stereotypes on structures for recruiting female coaches to soccer clubs. European Journal for Sport Society. 2013;10(3):241-65.

21. Welford J. Tokenism, ties and talking too quietly: Women's experiences in non-playing football roles. Soccer Society. 2011;12(3):365-81.

22. Siegele JL, Smith AB, Hardin R. Male collegiate student-athletes' experiences and perceptions of female head coaches. Journal for the Study of Sports Athletes in Education. 2019;13(1):30-52.

23. Jones C, Edwards LL. The woman in black: Exposing sexist beliefs about female officials in elite men's football. Sport Ethics Philosophy. 2013;7(2): 202-16.

24. Kamphoff CS. Bargaining with patriarchy: Former female coaches' experiences and their decision to leave collegiate coaching. Res Q Exerc Sport. 2010;81(3):360-72.

25. Tingle J, Warner S, Sartore-Baldwin ML. The experience of former women officials and the impact on the sporting community. J Res. 2014;71(1-2):720.

26. Department of Health. Sport 2030. Commonwealth of Australia; 2018.

27. International Olympic Committee. IOC gender equality review project. 2018 [cited 2020 31st August]; Available from: https://stillmed.olympic.org/media/ Document\%20Library/OlympicOrg/News/2018/03/IOC-Gender-EqualityReport-March-2018.pdf.

28. Victoria State Government. Change our Game. undated [cited 2020 2nd June 2020]; Available from: https://sport.vic.gov.au/our-work/participation/ change-our-game.

29. Sport New Zealand, Women and girls in sport and active recreation: Government strategy. 2018, New Zealand. p. 11.

30. Sport Australia. Second AusPlay Methodology Report July 2016 - June 2017. 2017 [cited 2018 5th March]; Available from: https://www.clea ringhouseforsport.gov.au/research/smi/ausplay/method.

31. Commonwealth of Australia, Gender Balance on Australian Government Boards Report 2018-19. 2018-19, Department of the Prime Minister and Cabinet.

32. Sharpe E. Resources at the grassroots of recreation: Organizational capacity and quality of experience in a community sport organization. Leisure Sciences. 2006;28:385-401.

33. Acosta RV, Carpenter $\mathrm{L}$, Woman in intercollegiate sport: A longitudinal, national study, thirty-seven year update, 1977-2014. 2014.

34. Kubayi A, Coopoo Y, Morris-Eyton H. Work-related constraints in sports coaching: Perceptions of South African female coaches. International Journal of Sports Science Coaching. 2017;12(1):103-8.

35. Wasend M, LaVoi NM. Are Women Coached by Women More Likely to Become Sport Coaches? Head Coach Gender and Female Collegiate Athletes' Entry into the Coaching Profession. Women in Sport Physical Activity Journal. 2019;27(2):85-93.

36. Hancock MG, Hums MA. A "leaky pipeline"?: Factors affecting the career development of senior-level female administrators in NCAA Division I athletic departments. Sport Management Review. 2016;19(2):198-210.

37. Penning MJ, Wu Z. Caregiver Stress and Mental Health: Impact of Caregiving Relationship and Gender. Gerontologist. 2015;56(6):1102-13.

38. Hancock MG, Darvin L, Walker NA. Beyond the Glass Ceiling: Sport Management Students' Perceptions of the Leadership Labyrinth. Sport Management Education Journal (Human Kinetics). 2018;12(2):100-9.

39. Cunningham GB, Dixon MA, Singer JN, Oshiro KF, Ahn NY, Weems A. A Site to Resist and Persist: Diversity, Social Justice, and the Unique Nature of Sport. Journal of Global Sport Management, 2019: p. 1-19. 
40. Hindman LC, Walker NA. Sexism in Professional Sports: How Women Managers Experience and Survive Sport Organizational Culture. Journal of Sport Management. 2020;34(1):64-76.

41. Darvin L, Sagas M. Objectification in Sport Media: Influences on a Future Women's Sporting Event. International Journal of Sport Communication. 2017;10(2):178

42. Harvey JT, Charity MJ, Sawyer NA, Eime RM. Non-response bias in estimates of prevalence of club-based sport participation from an Australian national physical activity, recreation and sport survey. BMC Public Health. 2018;18(1):895.

\section{Publisher's Note}

Springer Nature remains neutral with regard to jurisdictional claims in published maps and institutional affiliations.

Ready to submit your research? Choose BMC and benefit from:

- fast, convenient online submission

- thorough peer review by experienced researchers in your field

- rapid publication on acceptance

- support for research data, including large and complex data types

- gold Open Access which fosters wider collaboration and increased citations

- maximum visibility for your research: over $100 \mathrm{M}$ website views per year

At BMC, research is always in progress.

Learn more biomedcentral.com/submissions 